\title{
Analisis Penerapan Breastfeeding Peer Counseling Pada Pasien Post Partum Fisiologis Dengan Masalah Keperawatan Menyusui Tidak Efektif Berdasarkan Teori Maternal Role Attainment-Becoming A Mother Ramona T. Mercer
}

\author{
Dwi Rahayu, Yunarsih \\ Akademi Keperawatan Dharma Husada Kediri \\ Email: alfarezapriyoputra@yahoo.com
}

\begin{abstract}
The postpartum period is a critical time for the mother of one side is happy at the same times stressful to adapt after childbirth. Adaptation includes adjusting to build a positive interaction with the baby. One of the problems that occur in the postpartum period is the failure of mothers in exclusive breastfeeding. The low exclusive breastfeeding for mothers because they do not know the benefits of breastfeeding for children's health. Support from father also affect the success of exclusive breastfeeding for six months. Mother's decision to breastfeed affected family members information about the benefits of breastfeeding, as well as a lactation consultant. The purpose of this study is to analyze specific interventions , namely breastfeeding peer Counseling to improve exclusive breastfeeding in the postpartum period using theory of nursing, Maternal Role Attainment - Becoming a Mother developed by Ramona T. Mercer. The method used in this paper is a case report on the Physiological Postpartum Mothers treated in Kabupaten Kediri Hospital. On The assessment results according to the theory of Ramona $\mathrm{T}$ Mercer in the antisipatori data obtained on the condition of pregnancy that the mother does not experience problems, the ANC program appropriate with the schedule of health workers. In the Formal assessment of the phase Formal acceptance by the baby's mother obtained the difficulty breast-feeding mother to baby and family support is still lacking. In the Informal phase obtained for fear the baby's mother in the care especially during the current bathing and cord care. In the personal phase obtained mother feel mother's role is very important in baby care. Breastfeeding Peer Counseling can be applied to postpartum mothers who experience difficulties with breastfeeding to their babies. The program is to motivate mothers to give babies the best nutrition to their infants through exclusive breastfeeding and provide psychological support to the mother to perform maintenance on the baby independently.
\end{abstract}

Keywords : Breastfeeding Peer Counseling, Postpartum mother, exclusive Breastfeeding selama empat hingga enam bulan.

\section{Pendahuluan}

Periode postpartum merupakan saat kritis bagi ibu salah satu sisi merupakan masa-masa membahagiakan sekaligus penuh dengan stress untuk beradaptasi setelah melahirkan. Adaptasi termasuk menyesuaikan dengan pasangan dan membangun interaksi positif dengan bayi (Fleming, et.al,1998).

Salah satu masalah yang terjadi pada masa postpartum adalah ketidakberhasilan ibu dalam memberikan ASI eksklusif. Pada tahun 2007 delapan belas persen ibu di Indonesia memberi ASI eksklusif Persentase itu jauh dari target nasional yaitu $80 \%$. Rendahnya pemberian ASI eksklusif karena para ibu belum mengetahui manfaat ASI bagi kesehatan anak. Dukungan dari ayah juga mempengaruhi keberhasilan pemberian ASI eksklusif selama enam bulan. Keputusan ibu untuk menyusui dipengaruhi informasi anggota keluarga tentang manfaat menyusui, serta konsultan laktasi (Wulandari, 2009).

Pemberian ASI secara eksklusif dapat menyelamatkan lebih dari tiga puluh ribu balita di Indonesia. Jumlah bayi di 
Indonesia yang mendapatkan ASI eksklusif terus menurun karena semakin banyaknya bayi di bawah 6 bulan yang diberi susu formula. Menurut Survei Demografi Kesehatan Indonesia (SDKI) dari 1997 hingga 2002, jumlah bayi usia enam bulan yang mendapatkan ASI eksklusif menurun dari $7,9 \%$ menjadi 7,8\%. Sementara itu, hasil SDKI 2007 menunjukkan penurunan jumlah bayi yang mendapatkan ASI eksklusif hingga 7,2\% dan jumlah bayi di bawah enam bulan yang diberi susu formula meningkat dari $16,7 \%$ pada 2002 menjadi $27,9 \%$ pada 2007 (Sutama, 2008).

Pemberian ASI sangat penting bagi tumbuh kembang yang optimal baik fisik maupun mental dan kecerdasan bayi. Oleh karena itu pemberian ASI perlu mendapat perhatian para ibu dan tenaga kesehatan agar proses menyusui dapat terlaksana dengan benar. ASI Eksklusif atau lebih tepat disebut pemberian ASI secara eksklusif, artinya bayi hanya diberi ASI saja, tanpa tambahan cairan lain, seperti susu formula, jeruk, madu, air teh, air putih, juga tanpa tambahan makanan padat, seperti pisang, pepaya, bubur susu, biskuit, bubur nasi ataupun tim mulai lahir sampai usia 6 bulan (Roesli, 2005).

Soetjiningsih (1997) menyatakan bahwa masih rendahnya cakupan ASI Eksklusif disebabkan oleh berbagai macam faktor, di antaranya adalah: (1) perubahan sosial budaya, (2) meniru teman, (3) merasa ketinggalan zaman,(4) faktor psikologis, (5) kurangnya penerangan oleh petugas kesehatan, (6) meningkatnya promosi susu formula, dan (7) informasi yang salah. Sebenarnya pemerintah telah serius meningkatkan cakupan ASI Eksklusif. Hal ini dibuktikan dengan dikeluarkannya Kepmenkes RI No. 450/MENKES/SK/ IV/2004 tentang Pemberian Air Susu Ibu (ASI) secara eksklusif pada Bayi di Indonesia. Keputusan ini memuat Sepuluh Langkah Menuju Keberhasilan Menyusui, di antaranya adalah menjelaskan kepada semua ibu hamil tentang manfaat menyusui, membantu ibu mulai menyusui bayinya dalam 30 menit setelah melahirkan yang dilakukan di ruang bersalin, tidak memberikan makanan atau minuman apapun selain ASI kepada bayi baru lahir, melaksanakan rawat gabung dengan mengupayakan ibu bersama bayi 24 jam sehari, dan tidak memberikan dot atau kempeng kepada bayi yang diberi ASI.

Asuhan keperawatan maternitas yang di berikan seorang perawat profesional sangat mempengaruhi kualitas pelayanan, khususnya pelayanan pasien pada masa postpartum. Mengingat kompleksnya permasalahan kesehatan ini maka perlu kemampuan professional perawat dan sehingga mampu melakukan intervensi yang tepat terhadap permasalahan pada ibu pada masa postpartum. Keperawatan maternitas dikembangkan dalam rangka menjawab tuntunan kebutuhan masyarakat saat ini dan tuntunan perkembangan profesi keperawatan melalui berbagai perannya sehingga mampu bekerja sebagai pemberi dan pengelola asuhan keperawatan, pendidik, peneliti, bimbingan dan konseling, menerima dan melakukan rujukan dalam mengatasi masalah pasien.

Perawat maternitas yang professional didalam memberikan asuhan keperawatan pada ibu postpartum harus berdasarkan konseptual keperawatan. Salah satu model konseptual keperawatan yaitu Maternal Role Attainment-Becoming a Mother yang dikembangkan oleh Ramona T. Mercer. Fokus utama dari teori ini adalah gambaran proses pencapaian peran ibu dan proses menjadi seorang ibu dengan berbagai asumsi yang mendasarinya.

Berdasarkan hal di atas penulis tertarik untuk menyusun dan mengaplikasikan intervensi khusus yaitu breastfeeding peer conseling untuk meningkatkan pemberian ASI eksklusif pada periode postpartum dengan menggunakan model konseptual keperawatan yaitu Maternal Role 
Attainment-Becoming a Mother yang dikembangkan oleh Ramona T. Mercer

\section{Metode Penelitian}

Tulisan ini merupakan hasil laporan kasus (case report) pada Ibu Postpartum Fisiologis yang di Rawat di RSUD Kabupaten Kediri yang mengalami ketidakefektifan menyusui. Asuhan keperawatan yang diberikan pada Ibu Postpartun Fisiologis tersebut dilakukan dengan pendekatan teori Maternal Role Attainment - Becoming a Mother yang dikembangkan oleh Ramona T. Mercer.

\section{Hasil Penelitian \\ Ranah Antisipatori \\ Riwayat Kehamilan dan Kelahiran \\ ANC (Antenatal care) \\ Trimester I : $\square 1$ kali $\sqrt{ } 2$ kali $\quad \square 3$ kali \\ Trimester II $\quad: \square 1$ kali $\sqrt{ } 2$ kali \\ Trimester III $\quad: \square 1$ kali $\square 2$ kali \\ Tempat ANC : tidakterkaji \\ Imunisasi TT : $\sqrt{ }$ Iya $\quad \square$ Tidak \\ Konsumsi Obat : :Tidak \\ Konsumsi Jamu : tidak \\ Keluhan kehamilan : tidak ada \\ Ada \\ Riwayat Psikologis}

a. Persepsi ibu tentang kehamilannya : Pada Kehamilan keduanya ini, memang direncanakan oleh pasangan suami istri ini, sehingga secara psikologis ibu sangat mengharapkan kelahiran bayinya secara normal dan bayinya dalam kondisi sehat.

b. Persepsi keluarga tentang kehamilannya :

Keluarga mendukung ibu dalam proses kehamilan, persalinan dan perawatan bayinya.

\section{Interaksi Selama Kehamilan}

a. Interaksi ibu dengan keluarga : Baik

b. Interaksi ibu dengan orang lain : Baik

\section{Harapan selama Kehamilan}

Ingin melahirkan secara normal dan kondisi bayi nya sehat.

\section{Peran yang dilakukan ibu selama kehamilan}

Sebagai ibu rumah tangga yang memiliki 1 putra berusia 6 tahun.I

\section{Ranah Formal}

1. Fase Penerimaan Bayi oleh Ibu Ibu menerima bayinya, tetapi ibu masih kesulitan dalam hal perawatan bayinya dan proses menyusui bayinya karena ASInya belum keluar dengan lancar.

2. Bonding Attachment

Terlaksana dengan baik, bayi tenang ketika disusui ibunya

3. Breast feeding / kolostrum

Sudah keluar tetapi belum lancar

4. Interaksi sosial selamb lkellahiran

Baik, ibu mampu bekinteraksi dengani perawat ataupun $\sqrt{3}$ parafien yang 3 lkini dengan baik

5. Peran ayah selama kelahiran

Ayah menunggu bayi dan ibunya dan memenyhitikgkutuhan yang dibutuhkan selama perawatan bayi dan ibu, meskipun di ruangan ini, keluarga hanya di ijinkan masuk ke ruangan selama jam besuk.

\section{Ranah Informal}

1. Orang yang terlibat dalam perawatan bayi

Ketika di rumah sakit, Ny. M diajari cara perawatan bayi meliputi memandikan dan merawat tali pusat. Dengan bekal ini diharapkan ibu bisa melakukanya secara mandiri ketika di Rumah.

2. Peran dalam perawatan bayi

Ibu mampu melakukan perawatan pada bayinya, meskipun masih agak takut ketika memandikan bayi

3. Pengalaman dalam perawatan bayi Pernah melakukan perawatan bayi pada anak pertamanya, tetapi perannya masih banyak dibantu oleh keluarga (orang tuanya) 
4. Harapan untuk perawatan bayi yang akan datang

Mampu melakukan perawatan bayi nya secara mandiri dan lebih baik

\section{Ranah Personal}

1. Pandangan ibu terhadap perannya

Ny. M merasa bahwa perannya dalam perawatan bayi ini sangat penting, untuk kesehatan bayinya dan menumbuhkan kontak batin antara ibu dan bayinya.

2. Pengalaman masa lalu yang mempengaruhi peran ibu

Ny. M merasa bahwa peranya pada masa lalu, ketika melahirkan anak pertama belum begitu nampak, karena banyak dibantu oleh keluarga

3. Percaya diri dalam menjalankan peran

Ny. M merasa masih takut ketika memandikan bayinya, dan merasa kurang yakin mampu memberikan ASI secara eksklusif, sehingga Ny. M memberikan PASI untuk mencukupi kebutuhan minum bayinya.

4. Pencapaian peran

Ny. M mempunyai minat yang besar dalam upaya pencapaian peran sebagai seorang ibu yang melakukan perawatan pada bayinya secara optimal.

\section{Pengkajian Bayi}

1. Temperamen bayi

Di status pasien tertulis : bayi menangis kuat

2. Apgar's Score 8- 9

3. Penampilan Umum

a. Tanggal Lahir: 10 Nopember 2014 pukul 21.45

b. Berat badan : 3300 gram

c. Panjang badan : $50 \mathrm{~cm}$

d. Lingkar kepala : $35 \mathrm{~cm}$

e. Lingkar dada : $32 \mathrm{~cm}$

f. RR : $38 \mathrm{x} /$ menit

g. Suhu $: 36^{\circ} \mathrm{C}$

h. Nadi : $140 \mathrm{x} / \mathrm{menit}$
4. Karakteristik umum

a. Usia bayi : 3 hari

b. Kepala : simetris

c. Fontanel anterior: teraba datar

d. Sutura : teraba dan belum menyatu

e. Postur : lengan dan tungkai fleksi

f. Hidung : tidak ada kelainan

g. Telinga : tidak ada kelainan

h. Mulut : tidak ada kelainan

5. Responsiveness

a. Kontak mata : bayi mampu untuk membuka mata

b. Reflek

Reflek morro : baik

Reflek rotting : baik

Reflek sucking : baik

Reflek tonick neck : baik

Reflek babinski : baik

\section{Terapi dan Pemeriksaan Laboratorium}

1. Terapi

ASI/PASI 8 x 20-25 cc

Amphicilin 2 x $165 \mathrm{mg}$ IV

Gentamicin 1 x 16 mg IV

Thermoregulasi

Rawat Tali pusat

\section{Diagnosa Keperawatan dan Rencana Keperawatan}

Diagnosa Keperawatan : Menyusui tidak efektif berhubungan dengan kurangnya kepercayaan diri ibu untuk memenuhi kebutuhan ASI pada bayinya.

Tujuan : meningkatkan kepercayaan ibu untuk memberikan ASI secara eksklusif pada bayinya sehingga proses menyusuinya menjadi efektif

Kriteria Hasil : Proses menyusui bisa efektif dan berhasil melakukan ASI Eksklusif

\section{Rencana Keperawatan :}

1. Kaji tentang kesehatan ibu post partum dan sesuaikan dengan kemampuan ibu untuk melakukan perawatan diri dan bayinya

2. Kaji kemampuan ibu dalam proses pemberian ASI 
3. Lakukan breastfeeding peer counseling untuk meninngkatkan kemampuan ibu dalam proses pemberian ASI kepada bayinya.

\section{Pembahasan}

Analisis Penerapan Teori Maternal Role Attainment - Becoming a Mother pada Ny. M Post Partum Fisiologis

Model Mercer memaparkan hal-hal yang seharusnya terindentifikasi dan memfasilitasi ibu agar mampu menerima dan melaksanakan peranannya sebagai ibu. Kemampuan ibu menerima peran sebagai ibu sejak awal akan meningkatkan ikatan ibu dengan bayi dan mendukung perkembangan kesehatan fisik dan mental ibu dan bayi sepanjang kehidupan. Bila ibu telah menerima perannya, maka ia akan berusaha menjalankan peran sebaikbaiknya, dan bila berhasil akan merasakan kepuasan. Kepuasan yang diperoleh merupakan kekuatan yang mendorong dalam memenuhi kebutuhan fisik dan psikologis ibu beserta bayinya. Namun model ini tidak dapat diterapkan pada ibu yang mengalami penurunan kesadaran dan gangguan jiwa, karena peran yang seharusnya dilaksanakan oleh ibu akan digantikan oleh orang lain atau keluarganya.

Mercer juga menekankan pentingnya dukungan suami dan keluarga sejak kehamilan, kelahiran dan setelah melahirkan. Pendekatan Mercer digunakan sejak awal sehingga kesiapan peran ibu dapat terdeteksi oleh perawat. Di Indonesia umumnya suatu kehamilan dan kelahiran akan disambut dengan sangat antusias oleh seluruh keluarga besar sehingga pengaruh keluarga sangat kuat dalam perawatan ibu dan bayi, justru peran ayah yang menjadi berkurang karena banyaknya dukungan dari keluarga besar. Disamping itu aturan atau kebijakann RS yang tidak mengijinkan suami atau keluarga menunggu istri selama proses melahirkan akan mengurangi interaksi orang tua dengan bayinya selama proses persalinan sehingga menurunkan proses pencapaian peran. Peran ayah yang aktif dalam proses persalinan maupun perawat bayi akan menunjukkan keterikatan yang lebih kuat dari pada ayah yang tidak terlibat dalam proses persalinan dan perawatan bayi (Reeder, 1997).

Pada awalnya model konseptual Mercer lebih lebih ditujukan pada pengkajian ibu post partum karena model ini berfokus pada proses pencapaian peran ibu dan bagaimana menjadi seorang ibu. Namun jika meninjau konsep model yang dikemukakan oleh Mercer ini bayi adalah bagian yang sangat penting dalam proses pencapaian peran tersebut, dimana interaksi bayi dengan ibu yang terjalin utuh dan sistematis akan mempererat kasih sayang antara keduanya.

Penerapan konsep model Mercer dalam praktek keperawatan maternitas dikenal sebagai bonding attachment. Bonding attachment adalah interaksi antara orang tua dengan bayinya yang dimulai sejak dalam kandungan, dilanjutkan saat proses persalinan serta dipertahankan selama dan setelah proses post partum. Pengertian bonding sendiri adalah dimulainya interaksi emosi, fisik dan sensoris antara orang tua dan bayinya segera setelah lahir ditampilkan melalui daya tarik satu arah oleh orang tua tehadap bayinya. Sedangkan attachment adalah ikatan perasaan kasih sayang antara oarang tua dengan bayinya meliputi pencurahan perhatian serta adanya hubungan emosi, fisik yang kuat berupa hubungan timbal balik yang saling menguntungkan melalui sinyal antara pemberi asuhan utama dan bayi yang berkembang secara berangsur-angsur. (Matterson, 2001)

Pengkajian terhadap bonding dapat dilakukan dengan melakukan observasi terhadap perilaku orang tua dengan mengenali bayinya, memberi nama dan mengakui adanya bayi sebagai anggota keluarga. Attachment meliputi pengkajian verbal dan non verbal ibu dan keluarga saat berinteraksi dengan bayinya, meliputi 
respon orang tua saat bayi menangis, apakah orang tau menunda pekerjaan atau kebutuhan dan berjalan mendekat, menerima tanggung jawab mengasuh bayinya dan melaksanakan perawatan pada bayi, merubah panggilan orang tua dengan panggilan yang diharapkan anak. (Mercer, 1995). Perilaku orang tua yang menunjukkan adanya bonding attachment adalah adanya sentuhan fisik dengan menyusui, sentuhan kulit, adanya kontak mata saat menyusui dan saat bayi terbangun, berbicara serta memeriksa tubuh bayi. Hal-hal tersebut sejalan dengan bagaimana Mercer menggambarkan bagaimana pencapaian peran menjadi ibu. Tetapi bonding attachment bisa terhambat pelaksanaannya jika di rumah sakit tersebut tidak fasilitas untuk melakukan rooming in sesuai dengan kondisi ibu dan bayi setelah post partum.

Mercer menegaskan pada teorinya bahwa proses pencapaian peran ibu yang dilalui dengan empat fase akan selalu berhubungan dengan respon bayi. Pada fase anticipatory yang dimulai sejak kehamilan, bayi juga dilibatkan untuk berinteraksi, lalu fase kedua yang dimulai saat kelahiran bayi yang juga memerlukan peran perawat dalam melakukan pengkajian fisik secara umum, model Mercer ini juga mendukung dengan pengkajian yang lebih difokuskan pada psikososial. Pada fase ketiga informal, peran ibu dalam proses interaksi dengan bayinya menjadikan ibu lebih matang di dalam menjalankan perannya. Fase keempat personal, ibu telah menginternalisasi perannya sehingga ibu mulai merasa percaya diri,merasa mampu dalam menjalankan tugasnya.

Model konseptual Mercer memandang bahwa sifat bayi berdampak pada identitas peran ibu yang meliputi : temperamen, kemampuan memberikan isyarat, penampilan, karakteristik umum, responsiveness dan kesehatan umum.Mercer juga mengembangkan teorinya pada bayi baru lahir yang lebih spesifik dengan mengkaji kontak mata antara bayi dengan ibunya sebagai isyarat pembicaraan,adanya refleks menggenggam, refleks tersenyum dan tingkah laku yang tenang sebagai respon terhadap perawatan yang dilakukan ibu. Konsistensi tingkah laku interaksi dengan ibu dan respon yang datang dari ibu akan meningkatkan pergerakan.

Meighan (2001), mengemukakan bahwa teori Mercer sangat relevan digunakan pada berbagai setting praktek keperawatan maternitas dan anak. Hal ini didasarkan pada hasil penelitiannya yang selalu dapat diaplikasikan dalam tatanan pelayanan keperawatan. Penerapan konsep Mercer ini lebih banyak terfokus pada kondisi psikologis dan fisik sedangkan pemenuhan kebutuhan dasar manusia tidak terkaji. Oleh karena itu agar dapat menggali data yang komprehensif konsep model Mercer ini harus dikombinasi dengan teori lain yang mencakup kebutuhan dasar manusia.

\section{Analisa Rekomendasi Breastfeeding Peer Counseling Dengan Masalah Keperawatan Menyusui tidak Efektif Pada Pasien Post partum Fisiologis.}

Guna mereview perlu adanya breastfeeding peer counseling pada ibu yang memberikan ASI, maka penulis mengkaji beberapa riset yang meneliti tentang hal tersebut. Pencarian artikel dilakukan secara elektronik. Pencarian tidak terbatas pada artikel penelitian yang diterbitkan oleh negara tertentu. Artikel yang digunakan diterbitkan pada tahun 2003 sampai 2013. Kombinasi kata kunci (key words) yang digunakan yaitu breastfeeding, peer, support. Pencarian menemukan 2 artikel. Pada makalah ini kami mereview 2 artikel yang berkaitan dengan upaya meningkatkan status nutrisi pada bayi dengan melakukan health promotion kepada ibu agar memberikan asupan nutrisi yang efektif dan maksimal dengan breastfeeding peer counseling.

Dari beberapa artikel diatas ditemukan bahwa breastfeeding peer 
counseling merupakan cara yang dilakukan untuk memberdayakan ibu yang menyusui degan meningkatkan motivasi, pengetahuan, sikap dan kepercayaan diri ibu untuk memberikan asupan ASI kepada bayinya. Breastfeeding peer counseling merupakan training/pelatihan yang didampingi oleh konselor/perawat dan beberapa ibu lain yang juga menyusui bayinya. Program ini meliputi pelatihan tentang teori (anatomy dan fisiologi payudara dan manajemen menyusui yang efektif), melakukan role play, praktik langsung kepada bayi, dan kemampuan komunikasi yang selalu dimonitor oleh konsultan secara rutin dan dilakukan home visit/ kunjungan rumah. Peer Conselor diobservasi selama 2 bulan oleh seorang konsultan laktasi yang mendampingi ibu dengan gangguan menyusui.

Intervensi ini sesuai apabila diterapkan pada Ny. M yang mengalami masalah dalam menyusui bayinya yang merasa kesulitan untuk memposisikan bayinya ketika menetek. penerapan intervensi ini juga dapat meningkatkan pengetahuan, kemampuan ibu, kepercayaan diri ibu dalam merawat bayi secara mandiri agar tidak mengalami malnutrisi yang dapat mempengaruhi tumbuh kembangnya dan bisa memberikan ASI secara Eksklusif kepada bayinya.

Dengan adanya peer counseling dari konsultan laktasi dalam hal ini bisa juga dilakukan oleh perawat maternitas dan support dari sesama anggota kelompok training/pelatihan laktasi dapat meningkatkan kemampuan ibu dalam memberikan ASI yang efektif pada bayi. Dalam peer / kelompok ibu bisa saling sharing dengan sesama ibu yang lain sehingga dapat meningkatkan pemahaman ibu mengenai pemberian ASI yang efektif.

Bayi baru lahir mempunyai resiko yang tinggi mengalami malnutrisi karena ketidakseimbangan antara intake yang didapat dan proses hipermetabolisme yang ada dalam tubuh. Perawat sebagai konselor dan educator harus memberikan health education dan konseling pada ibu tentang manajemen laktasi yang efektif agar dapat meningkatkan nutrisi pada bayi baru lahir.

\section{Kesimpulan \& Saran \\ Kesimpulan}

1. Penerapan konsep dari teori Maternal Role Attainment-Becoming a Mother ini tepat digunakan untuk melakukan pengkajian pasien post partum untuk mencapai adaptasi perubahan fisiologis ataupun psikologis pada masa postpartum sehingga bisa mencapai peran yang diharapkan dalam perawatan diri dan bayinya.

2. Breastfeeding Peer Counseling dapat diaplikasikan pada ibu postpartum yang mengalami kesulitan dalam hal pemberian ASI kepada bayinya. Program ini untuk memotivasi ibu bayi agar memberikan nutrisi terbaik pada bayinya melalui ASI Eksklusif dan memberikan support kepada ibu secara psikologis untuk melakukan perawatan pada bayinya secara mandiri.

\section{Saran}

1. Bagi praktek keperawatan

Intervensi Breastfeeding Peer Counseling dapat diterapkan tidak hanya pada menyusui saja tetapi pada penatalaksaan faktor psikologis ibu terkait ketidakpercayadirian ibu dalam pemberian ASI secara Eksklusif yang membutuhkan support dari kelompok untuk sharing mengenai masalah pemberian ASI secara Eksklusif

2. Bagi riset keperawatan

Perlu dilakukan penelitian lebih lanjut mengenai intervensi lain yang digunakan untuk meningkatkan helth promotion khususnya masalah pemberian ASI secara Eksklusif dan proses untuk meningkatkan kualitas produksi ASI sehingga ibu tidak kuatir 
dalam pemberian nutrisi pada bayinya.

\section{Daftar Pustaka}

Alex K. Anderson, P; Grace Damio\& etc . (2005). A Randomized Trial Assessing the Efficacy of Peer Counseling on Exclusive Breastfeeding in a Predominantly Latina Low-Income Community. Arch Pediatric Adolesc Med. 2005;159:836-841

Bobak, I.M., Lowdermilk, D.L., \& Jensen, M.D. (2005). Buku ajar keperawatan maternitas. (edisi 4). Jakarta: EGC.

Casey, P.H., Mansell, L.M., Barrett, K., Bradley, R.H., \& Gargus, R. (2006). Impact of prenatal and/or postnatal growth problems in low birth weight preterm infants on school-age outcomes: An 8-year longitudinal evaluation. Pediatrics, 118(3), 1078-1086

Chin P.L.\& Kramer. 1997. Theory and Nursing : A System Approach. Sint Louis: Mosby Company.

Doengoes Merillynn. (1999) (Rencana Asuhan Keperawatan). Nursing care plans. Guidelines for planing and documenting patient care. Alih bahasa : I Made Kariasa, Ni Made Sumarwati. EGC. Jakarta.

Dorland. (1998). Kamus Saku Kedokteran Dorland. Alih Bahasa: Dyah Nuswantari Ed. 25. Jakarta: EGC

Esther HY Wong1, EAS Nelson. (2007). Evaluation of a peer counselling programme to sustain breastfeeding practice in Hong Kong. International Breastfeeding Journal 2007, 2:12 doi:10.1186/1746-43582-12
Judith M.W .(2005) Prentice Hall Nursing Diagnosis Handbook With NIC Intervention and NOC Outcomes. Pearson

Marriner-Tomey \& Alligood (2006). Nursing theorists and their works. 6th Ed.St.Louis:Mosby Elsevier, Inc

Merestein, G.B \& Gradner, S.L (2002). Handbook of neonatal intensive care $\left(5^{\text {th }}\right.$ ed) St. Louis : Mosby.

Riset Kesehatan Dasar (Riskesdas) Nasional 2010. Jakarta: Badan Penelitian dan Pengembangan Kesehatan Depkes RI.

Taylor C., Lilis, C., LeMone, P. 1995. Fundamental of Nursing the Art and Science of Nursing Care. Philadelphia: Lippincot

Tomey, A.M., \& Alligood, M.R. 2006. Nursing Theorists and their Work, 4th Edition. St.Louis: Mosby.

Tomey, M.A. 1994. Nursing Theorist and Their Work. St. Louis : Mosby Company 